\title{
(2) OPEN ACCESS \\ Cross-sectional survey of the wish to die among palliative patients in Spain: one phenomenon, different experiences
}

\section{Alazne Belar (10 , 1,2 Maria Arantzamendi, ${ }^{1,2}$ Yolanda Santesteban, ${ }^{3}$ Jesús López-Fidalgo, ${ }^{4}$ Marina Martinez, ${ }^{2,5}$ Marcos Lama, ${ }^{6}$ Maria Rullán, ${ }^{1}$ Inés Olza, ${ }^{1}$ Ruth Breeze, ${ }^{1}$ Carlos Centeno (iD) 1,2,5}

\begin{abstract}
Instituto Cultura y Sociedad, Universidad de Navarra, Pamplona, Navarra, Spain 2IdiSNA, Pamplona, Navarra, Spain

${ }^{3}$ Obra Social LaCaixa, Hospital San Juan de Dios Pamplona, Pamplona, Navarra, Spain ${ }^{4}$ Institute of Data Science and Artificial Intelligence, Universidad de Navarra, Pamplona, Navarra, Spain

${ }^{5}$ Clínica Universidad de Navarra, Servicio de Medicina Paliativa, Clínica Universidad de Navarra, Pamplona, Navarra, Spain

${ }^{6}$ Servicio Navarro de Salud - Osasunbidea, Pamplona, Navarra, Spain
\end{abstract}

\section{Correspondence to} Maria Arantzamendi, Instituto Cultura y Sociedad, Universidad de Navarra, Pamplona, Navarra, Spain; marantz@unav.es

Received 30 January 2020 Revised 15 May 2020 Accepted 25 May 2020 Published Online First 24 June 2020

\section{Check for updates}

(c) Author(s) (or their employer(s)) 2021. Re-use permitted under CC BY-NC. No commercial re-use. See rights and permissions. Published by BMJ.

\footnotetext{
To cite: Belar A, Arantzamendi $\mathrm{M}$, Santesteban Y, et al. BMJ Supportive \& Palliative Care 2021:11:156-162.
}

\section{ABSTRACT}

Objective Cultural backgrounds and values have a decisive impact on the phenomenon of the wish to die (WTD), and examination of this in Mediterranean countries is in its early stages. The objectives of this study were to establish the prevalence of WTD and to characterise this phenomenon in our cultural context.

Methods A cross-sectional study with consecutive advanced inpatients was conducted. Data about WTD (Assessing Frequency \& Extent of Desire to Die (AFFED) interview) and anxiety and depression (Edmonton Symptom AssessmentSystem-revised (ESAS-r)) were collected through two face-to-face clinical encounters. Data were analysed with descriptive statistics, $\chi^{2}$ and analysis of variance.

Results 201 patients participated and 165 (82\%) completed both interviews. Prevalence of WTD was $18 \%(36 / 201)$ in the first interview and $16 \%(26 / 165)$ in the second interview $(p=0.25)$. After the first interview, no changes in depression $(p=0.60)$ or anxiety $(p=0.90)$ were detected. The AFFED shows different experiences within WTD: $11 \%$ of patients reported a sporadic experience, while $7 \%$ described a persistent experience. Thinking about hastening death (HD) appeared in 8 (22\%) out of 36 patients with WTD: 5 (14\%) out of 36 patients considered this hypothetically but would never take action, while 3 (8\%) out of 36 patients had a more structured idea about HD. In this study, no relation was detected between $\mathrm{HD}$ and frequency of the appearance of WTD $(p=0.12)$.

Conclusions One in five patients had WTD. Our findings suggest the existence of different experiences within the same phenomenon, defined according to frequency of appearance and intention to hasten death. A linguistically grounded model is proposed, differentiating the experiences of the 'wish' or 'desire' to die, with or without HD ideation.

\section{INTRODUCTION}

There is now growing interest in studying the phenomenon of the wish to die (WTD) in the clinical and research setting. ${ }^{1-4}$ Studies discuss the multifactorial nature of this phenomenon, taking in the influence of physical, psychosocial, spiritualexistential and social factors ${ }^{1}$ or those related to the patient's personal characteristics. The experience of WTD has been described as a dynamic phenomenon, which fluctuates over time, ${ }^{5-9}$ and which may form part of the process of adapting to illness. ${ }^{10}$ There may be coexisting, contradictory sentiments of WTD and wishing to live at the same time. ${ }^{9}$ These characteristics make WTD a complex phenomenon, in which it is necessary to examine in depth each person's experience. The available data on its prevalence are variable, ranging between $11 \%$ and $55 \%$ in different studies. As to the variability of data, the influence of the complexity of the experience and the diverse cultural contexts in which each study is undertaken are undeniable. ${ }^{311-20}$

Over the last 5 years in Spain, the situation of the wish to hasten death (WTHD) and its associated factors have been investigated. The first study was published in 2014, with the objectives of examining the validity and reliability of the Spanish version of Schedule of Attitudes toward Hastened Death (SAHD) and exploring factors associated with the WTHD. ${ }^{21}$ The results showed that SAHD has good psychometric properties, but 
professionals reported that in our cultural context, the questionnaire proved difficult to use, due to language that is perceived by Spanish patients as strong or overly direct. In this study, the WTHD was associated with emotional distress and patients' functional status. ${ }^{21}$ Another study compared two different approaches to assessing WTHD: the short form of the Schedule of Attitudes toward Hastened Death (SAHD-5) and the Desire for Death Rating Scale (DDRS). ${ }^{22}$ The results showed that these two methods may provide complementary information: the SAHD-5 as a screening tool and the DDRS as a clinical interview to explore the phenomenon in greater detail.

Porta-Sales et al designed a four-item interview guide (Assessing Frequency \& Extent of Desire to Die (AFFED)) adapted to our cultural setting. ${ }^{23}$ It was based on the experience of conversations on the WTD with patients, which allowed us to note the frequency, characteristics and reasons for considering this. A study was undertaken at an oncology hospital in Catalonia to see whether an AFFED-guided clinical interview would be upsetting for the patient. Most patients (95\%) accepted the interview using AFFED questions, and reported no negative feelings. The AFFED guide was also used in another study, showing that WTHD was significantly associated with perceptions of dignity and control. ${ }^{24}$

In our setting, the exploration of reasons for the WTD is thus recent and limited to the studies cited from Catalonia. The present study was designed to determine the prevalence of the WTD in a Spanish population with patients from different regions, to go deeper into the characteristics of this phenomenon (frequency and extension) and the implications of examining it by means of a clinical interview (stability and repercussion on their emotional status).

\section{METHODS}

A transversal study was designed to explore the experience of the WTD among patients receiving specialised palliative care (PC) at two hospitals in Pamplona. Participants were from all over the country: $36 \%$ had been born in the region of Navarra and 64\% were from different regions.

Inclusion criteria were (1) advanced stage illness; (2) expectancy of death in the short term, estimated via 'surprise question' with a time frame of 1 year by the patient's attending physician; (3) awareness of their diagnosis; (4) intact cognitive capacity; and (5) ability to understand Spanish well. Exclusion criteria were (1) final days' situations and (2) clinical context which advised against interview, following the attending physician's criteria, with notes taken as to reasons for exclusion.

\section{Data collection}

Data were collected between January and November 2018. Two interviews were planned for each patient, conducted by an experienced palliative care researcher with a nursing background, clinical experience at the bedside of patients with advanced conditions and trained in difficult conversations with patients. On the first day, sociodemographic and clinical data were collected and a semistructured interview was carried out on the WTD, using the AFFED questionnaire. Symptom intensity was evaluated using the Edmonton Symptom Assessment System-revised (ESAS-r) questionnaire. At 48-72 hours, the interview was repeated with the AFFED questionnaire and the ESAS-r was once again applied. Patients received standard care during the study. When the experience of WTD was detected and after patient consent during the interview, the care team was informed so they could address this in the course of patient care.

\section{Instruments}

The AFFED interview guide was created to examine the phenomenon of WTD in our cultural setting. It is designed to hold a short, simple, respectful conversation which can be easily applied in clinical practice. Using four successive questions, existence, frequency, extension and potential causes are examined. The interview begins with an indirect question to detect the existence of the phenomenon. After the sense of the initial response has been verified, a binary answer is recorded (yes/no); when the response is clearly affirmative, the researcher continues by examining the frequency of occurrence (almost never; sometimes; not every day, but almost every day; everyday). The extension of the phenomenon is established, keeping in mind which people are affected and above all, if the wish is accompanied, or not, by the idea of hastening death (HD) (eg, it has only been considered by the patient themselves; it has also been the subject of discussion with somebody else; they have thought of ending their own lives but they would never do it; they have thought about ending their lives in some way). In this study, HD includes different thoughts or actions about ending life, encompassing suicidal ideation. The final question examines the potential causes of this situation in the patient's eyes (pain or other symptoms; psychological aspects; social aspects; beliefs or values; other reasons, which are recorded).

The ESAS-r is a symptom evaluation survey, with a verbal numerical scale, on the 10 most common symptoms in advanced stage illness, including anxiety and depression. ${ }^{2526}$

\section{Statistical analysis}

A descriptive statistical analysis was carried out on the results obtained with the AFFED guide. The relationship between the dimensions of the frequency of appearance and extension were established using $\chi^{2}$. Calculations were made in the changes shown in the variables of presence of WTD, anxiety and depression after the initial interview, using analysis of variance 
(ANOVA). Analysis was carried out using STATA V.15 (StataCorp LP, College Station, Texas, USA). Results with $\mathrm{p}<0.05$ were deemed significant.

\section{RESULTS}

A total of 475 patients were admitted during the study period to the hospitals but just 234 (49\%) met the inclusion criteria. Of those who met the inclusion criteria, $201(86 \%)$ took part in the study: 31 patients refused to talk about profound aspects and 2 patients' relatives considered it better for the patient not to participate. Of the 201 inpatients who participated in the first interview, 165 (82\%) did the second interview, with an average interval of 3.5 days. Ten patients did not repeat the interview because they did not wish to discuss the subject again, and 26 for reasons unconnected to the matter being studied. Interviews lasted between 20 and $60 \mathrm{~min}$.

The patients' sociodemographic characteristics are shown in table 1 . Average age was 67 years and $46 \%$ were female. The majority claimed to hold religious beliefs (86\%) as usual considering the country's history and tradition, almost all of them were aware of the diagnosis (97\%) and the Karnofsky score for 76\% of patients was between 50 and 70 .

In the population studied, $36(18 \%)$ out of 201 patients claimed at interview to have experienced, in some way, the WTD (see table 2): 22 (11\%) occasionally, 3 (2\%) nearly every day, 11 (5\%) every day. The rest said they had never or almost never felt that way. Among those patients who had experienced the WTD, $8(22 \%)$ out of 36 had considered the idea of $\mathrm{HD} ; 5$ described a more hypothetical idea of HD, because they said they would not go through with it; 3 had more consistent ideas of HD, 1 of whom spontaneously manifested suicidal ideation. No premature death was recorded among the patients interviewed.

There was no association between the experience of HD in these eight patients and the frequency of the appearance of the WTD $\left(\chi^{2}, p=0.151\right)$ (table 3 ). Neither was any association found by dichotomising the item concerning frequency of the WTD, as 'sporadic' (sometimes) or 'persistent' (everyday or almost every day) against the existence, or not, of the HD $(\mathrm{p}=0.12)$ (table 4).

We examined whether there were changes in the existence of the WTD phenomenon between the two interviews. In the first interview, the WTD was present in $18 \%$, and in the second in $16 \%$, and no significant differences were detected (ANOVA, $\mathrm{p}=0.25$ ). During these days, patients received standard palliative care.

No significant changes were detected either between the two interviews, or on the anxiety $(p=0.90)$ or depression $(p=0.60)$ levels measured with the ESAS-r.

The reasons for WTD referred to by patients were pain or other symptoms (33\%), psychological aspects (33\%), the feeling of being a burden on the family (24\%), existential aspects (8\%) and a poor perception

\begin{tabular}{|c|c|}
\hline Total patients $(\mathrm{N}=201)$ & $\mathrm{N}(\%)$ \\
\hline Age (n, range) & $67(23-94)$ \\
\hline Sex: Female & $92(46)$ \\
\hline \multicolumn{2}{|l|}{ Occupation } \\
\hline Retired & $132(66)$ \\
\hline Employed & $32(16)$ \\
\hline Homemaker & $4(2)$ \\
\hline Other & $33(16)$ \\
\hline \multicolumn{2}{|l|}{ Educational level } \\
\hline Without studies & $3(1)$ \\
\hline Primary school & $74(37)$ \\
\hline High school & $35(18)$ \\
\hline Vocational training & $31(15)$ \\
\hline University & $58(29)$ \\
\hline \multicolumn{2}{|l|}{ Marital status } \\
\hline Single & $27(13)$ \\
\hline Married or with a partner & $120(60)$ \\
\hline Widower & $27(13)$ \\
\hline Separated, divorced & $17(9)$ \\
\hline Other & $10(5)$ \\
\hline \multicolumn{2}{|l|}{ Religious practice } \\
\hline Practising and believer & $94(47)$ \\
\hline Non-practising and believer & $78(39)$ \\
\hline Not believer & $29(14)$ \\
\hline History of depression & $23(11)$ \\
\hline History of anxiety disorder & $15(7)$ \\
\hline \multicolumn{2}{|l|}{ Primary tumour } \\
\hline Gastrointestinal system & $63(32)$ \\
\hline Respiratory system & $42(21)$ \\
\hline Reproductive system & $45(22)$ \\
\hline Excretory system & $23(11)$ \\
\hline Others & $25(14)$ \\
\hline Amyotrophic lateral sclerosis & $3(1)$ \\
\hline Chronic disease & $1(1)$ \\
\hline \multicolumn{2}{|l|}{ Information } \\
\hline Suspect or known diagnostic but does not speak & $5(3)$ \\
\hline Diagnostic but not prognostic & $97(48)$ \\
\hline Diagnostic and prognostic & $99(49)$ \\
\hline \multicolumn{2}{|l|}{ Treatment received (last 3 months) } \\
\hline None & $48(24)$ \\
\hline QT & $89(44)$ \\
\hline RT & $20(10)$ \\
\hline $\mathrm{QT}+\mathrm{RT}$ & $12(6)$ \\
\hline Other & $32(16)$ \\
\hline \multicolumn{2}{|l|}{ Functional status (Karnofsky) } \\
\hline$<50$ & $23(11)$ \\
\hline $50-70$ & $151(76)$ \\
\hline$>70$ & $27(13)$ \\
\hline
\end{tabular}

QT, chemotherapy; RT, radiotherapy.

of their own dignity (2\%). Twenty-six per cent referred to more than one reason for WTD.

\section{DISCUSSION}

In this study, nearly one in every five patients interviewed admitted to having experienced, to some 
Table 2 AFFED interview guide results

AFFED interview guide

Total N (\%)

Question 1 (Q1):

$\mathbf{R}$ Some people in your situation may involuntarily start to think that living like this is not worth it any more. Lately (in the last week or two) have you thought that living like this is not worth it? $(N=201)$

No, never

$158(78)$

Seldom/almost ever

7 (3)

Occasionally/sometimes

$22(11)$

Not every day but almost every day

$3(2)$

Every day

$11(5)$

E Question 2 (Q2):

$\mathrm{X}$ When you have had this thought or feeling, have you only

$\mathrm{T}$ thought about it (that you wanted to die) or have you E gone further? $(N=36)$

N Only thought about it

Have talked about/mentioned it to someone

$18(50)$

o Have thought about ending life, but never

$5(14)$

N would do it

Yes, there is a plan- they may or may not be able to explain it

$\begin{array}{llc}\text { C } & \text { Question } 3(\mathbf{Q 3}) \text { : } \\ \text { A } & \text { What makes you think or feel like that? }(\mathbf{N = 3 6 )} \\ \text { U } & \text { Pain or other symptoms } & 17(48) \\ \text { S } & \text { Psychological aspects } & 18(50) \\ \text { E } & \text { Social or relational aspects } & 11(31) \\ \text { S } & \text { Beliefs/values } & 2(6) \\ & \text { Other motives } & 3(8)\end{array}$

Translation: Q1: Algunas personas en su situación, aunque a veces no lo desean, llegan a pensar que vivir así no vale la pena. En las últimas semanas, ¿ha pensado -alguna vez -algo así?

Q2: Cuando ha tenido este pensamiento / sentimiento, ¿solo lo ha pensado o ha ido más lejos (haciendo referencia a si ha considerado adelantar la muerte)?

Q3: ¿Qué le hace pensar o sentirse así?

AFFED, Assessing Frequency \& Extent of Desire to Die.

extent, a type of WTD. This is the second study on the subject undertaken in our country with advanced patients, using a similar method based on personal patient interviews. The similarities between the two studies are important regarding the suitability of the method used to research the WTD. Our study thus provides independent confirmation that the AFFED as proposed by Porta $e t a^{23}$ is a feasible, innocuous
Table 4 Relationship between the frequency of the WTD (Q1) and considering hastening death (Q2) $(n=36)$ using AFFED

\begin{tabular}{llll}
\hline & $\begin{array}{l}\text { Without } \\
\text { considering } \\
\text { hastening } \\
\text { death } \neq\end{array}$ & $\begin{array}{l}\text { Considering } \\
\text { hastening } \\
\text { death§ }\end{array}$ & Total \\
Q1 response & 19 & 3 & 22 \\
\hline Sporadic* & 9 & 5 & 14 \\
Persistent† & 28 & 8 & 36 \\
\hline Total & & &
\end{tabular}

$\mathrm{p}=0.120$.

*Included patients that answer Q1 'occasionally/sometimes'.

tIncluded patients that answer Q1 'every day' or 'almost every day'.

fIncluded patients that answer Q2 'only thought about it' or 'have talked about/mentioned it to someone'.

§Included patients that answer Q2 'Have thought about ending life, but never would do it' or 'Yes, there is a plan — they may or may not be able to explain it'.

AFFED, Assessing Frequency \& Extent of Desire to Die; WTD, wish to die.

method for use with advanced patients. Nearly all the patients were receptive to the interview with the questions as planned (even when repeated a second time). Moreover, earlier results were confirmed in that the research method does not prove upsetting, and we might add that there are no significant changes observed in levels of anxiety and depression measured on ESAS-r over the following days. In summary, the AFFED interview guide is confirmed as a suitable guide to examine the phenomenon of the WTD in our setting.

In the other study cited, ${ }^{23}$ the prevalence of the WTD was seven percentage points higher. This small difference may be explained by the difference in the way of categorising the existence of the experience of the WTD in the two studies, as well as some differences in the characteristics of the patients taking part. In our study, the response by seven patients of having experienced the WTD, just sporadically, or on isolated occasions, equated to the response of not having felt the WTD. There are two reasons for this: on the one hand, the answer 'almost never' is much closer to 'no' than to repeated existence; on the other hand, the context of the interviews makes us suspect that some advanced patients might answer 'almost never', as a way of not negating the fact that sometimes the idea of

Table 3 Relation between frequency of occurrence of the phenomenon (Q1) and the extension of the phenomenon (Q2) ( $\mathrm{n}=36$ ) using AFFED

\begin{tabular}{|c|c|c|c|c|c|}
\hline $\begin{array}{l}\text { Q2 response } \\
\text { Q1 response }\end{array}$ & $\begin{array}{l}\text { Only thought } \\
\text { about it }\end{array}$ & $\begin{array}{l}\text { Have talked about/ } \\
\text { mentioned it to } \\
\text { someone }\end{array}$ & $\begin{array}{l}\text { Have thought about } \\
\text { ending life, but never } \\
\text { would do it }\end{array}$ & $\begin{array}{l}\text { Yes, there is a plan- } \\
\text { they may or may not } \\
\text { be able to explain it }\end{array}$ & Total \\
\hline Occasionally/sometimes & 7 & 12 & 3 & 0 & 22 \\
\hline Not every day, almost every day & 0 & 2 & 1 & 0 & 3 \\
\hline Every day & 2 & 5 & 1 & 3 & 11 \\
\hline Total & 9 & 19 & 5 & 3 & 36 \\
\hline
\end{tabular}

$\mathrm{p}=0.151$.

AFFED, Assessing Frequency \& Extent of Desire to Die. 


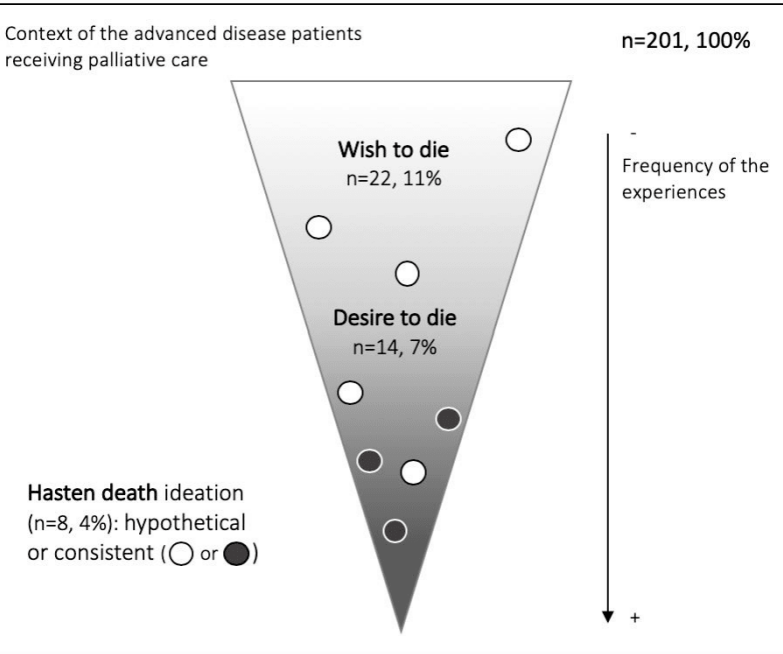

Figure 1 Different experiences of the 'wish to die' considering the frequency of occurrence of the phenomenon and the existence or not of hasten death ideation, in a sample of 201 Spanish patients $\left({ }^{*}\right)$. *We consider that a patient has experienced the 'wish to die' if he/she mentions having experienced it at some time. When this experience occurs every day or almost every day, we consider it a 'desire to die'. The idea of 'hastening death' might be present occasionally in both experiences, and may be either hypothetical or consistent.

dying is indeed present. If we applied this criterion to both studies, the data on prevalence would be identical for the study on patients from different regions and that with patients solely from Catalonia.

Among the patients who experienced a significant WTD, the AFFED guide, which examines the frequency of the presence of the WTD, allowed us to determine that half of the patients had sporadic experiences and the other half, a more persistent experience. Studies outside the Spanish context have estimated similar percentages considering the patients' different experiences: between $11 \%$ and $45 \%$ of patients report the WTD in a transitory or occasional way ${ }^{311-20}$ and in 3\%-20\% of the cases, these feelings or thoughts are more persistent. ${ }^{311-13} 15-1927$

In our study, data on prevalence did not see significant changes when the questions were repeated by means of the AFFED survey. Other studies suggest a diminished presence of the WTD merely as a result of the questioning process. ${ }^{28} 29$

Among patients who experienced the WTD, only a fifth claimed to have considered the idea of HD, independently of whether the WTD was more or less frequent. In the Catalonian study, ${ }^{23}$ only 1 out of 10 patients claimed to have thought of HD and this idea was related to experiencing the WTD with greater frequency. The spontaneous expression of suicidal ideation in one of the patients interviewed shows the need for further studies exploring this issue, since it is possible that in this study someone else had this, but it was not explored.
Analysing AFFED results also proved very useful for an in-depth study of different experiences. The results reveal the existence of one group of patients with sporadic experiences, another with more persistent wishes and a few from both groups in whom the idea of HD was also present. Other studies suggest the existence of diverse experiences but do not distinguish the frequency of appearance, or the presence of ideas of cutting one's life short. ${ }^{130}$

Our study shows that patients have different experiences within the broader experience of WTD. This result underlies the importance of understanding these experiences from the forefront of the patients' reality and taking the various nuances into consideration. When describing these experiences, linguistics also plays an important role. A consensus definition of the global phenomenon of WTD was recently accepted in which one of the authors of this paper participated. ${ }^{31}$ This consensus was based on the health professionals' perspective, and the decision was made to refer to the WTD as a 'Wish to Hasten Death'. The analysis of our results leads us to prefer using the expression 'Wish to Hasten Death' only for situations in which this idea is truly identified in the patient's experience. Thus, the need for a more fine-tuned definition of patients' experiences should be emphasised.

With the aim of adjusting the terms used in the different experiences, results were discussed with two language experts from the University of Navarra, one English (RB) and one Spanish (IO). A linguistic analysis was conducted which discussed specific terms in order to understand and characterise the phenomenon and provide the terminological clarity which literature demands. ${ }^{5} 213233$ The way of examining the WTD proposed in the AFFED distinguishes between two different domains (frequency and extension), while the responses to the AFFED obtained in this study present three different experiences: one of a sporadic nature (sometimes), another persistent experience (always or almost always) and a third, with a different idea, referring to HD. As can be seen below, the lexical analysis allows us to identify each of these situations with precise terms: 'wish to die', 'desire to die' and 'hastening death' (see figure 1).

Within the context of illness and aspiring to good health, the term 'wish' would be applied to a passing feeling, overridden as a hypothetical wish, or something out of reach or impossible, without any necessary proactive attitude to pursuing what one wants. In clinical practice, transitory situations are observed in diverse circumstances (pain, emotions, loneliness and so on) which lead to a reactive experience of WTD. This experience nearly always ceases when the cause disappears. The term 'WTD', in its strictest sense, would refer to sporadic or reactive experiences which, described in the AFFED guide, are referred to as 'sometimes'. 
On other occasions, patients present an ongoing, persistent experience. In this case it is more appropriate to use the term 'desire' and not 'wish'. Semantically, a desire is associated with a more intense, proactive attitude towards obtaining what one wants or what one intensely anticipates or which is so highly wished for. In clinical practice, we observe patients in whom the experience of desire to die becomes somewhat more intense and ingrained in the person, transforming them into a voluntary, conscious agent of achieving this desire. The desire to die includes these persistent experiences.

In both situations (WTD and desire to die), the intention of HD may be present, or not, as a possible course of action, or even as a solely hypothetical situation. Only in these special cases, in contrast to those which exclude the idea of bringing the end nearer, should the expression 'hasten death' be added.

For the linguists consulted, for international consensus $^{31}$ and for other authors, 'to wish' would be the appropriate verb to refer to the overall phenomenon. 'Wish to die' is a rather less acute expression and is more general than 'desire to die', the more semantically specific, concrete term.

Therefore, within a common phenomenon, where the overall idea might be referred to as 'wish to die', there are three different experiences, which are referred to as 'wish to die', 'desire to die' and the wish or desire 'to hasten death', respectively. This conceptual proposal is what would be already insinuated in the distinction made by Chochinov et al, ${ }^{11}$ when differentiating patients with a sporadic 'wish to die', as opposed to others who present a 'desire to die'. Although the conceptual proposal emerges from a study carried out in Spain, it may be useful in other cultures and it is up to future studies and researchers to determine its validity. Defining each experience with its corresponding term in other publications might help us achieve a deeper understanding of the complexity involved in experiencing the 'wish to die'.

\section{Study limitations}

The exploration of the WTD experience shows that it is innocuous within a range of 2-16 days, but we consider it would be beneficial to study whether its apparent harmlessness remains stable over a longer period of time. On the other hand, the discussion between clinical experts and linguists concerning the experience of WTD was conducted within the Spanish sociocultural context; it would be interesting to explore this subject in other sociocultural contexts.

\section{Clinical implications}

Data show that the experience of the WTD is common in patients with advanced illness, and talking about it in a sensitive way proves harmless. These results may encourage professionals to explore systematically the experience of WTD without fear that this could be harmful for the patient. Concerning family and patients, this commonality may contribute to a certain normalisation of the experience, enabling more sincere and open communication about this experience between them. Moreover, the different experiences within the same phenomenon uncovered in this study provide deeper knowledge of the overall phenomenon. More profound insights into different experiences of this kind may help care professionals to achieve a greater understanding of the patients' experience and thus provide better follow-up. This also may improve the comprehensive support for the patient's relatives, who may suffer as a consequence of being exposed to the patients' WTD. A terminological distinction between the different experiences involved may also contribute to more detailed research about this phenomenon, and further studies should be conducted to explore relationships between different experiences and associated factors (ie, disease).

Twitter Maria Arantzamendi @marantzamendi

Acknowledgements We would like to thank the multidisciplinary teams in our two partner hospitals who collaborated enthusiastically with the research team in data collection.

Contributors $\mathrm{AB}, \mathrm{MA}$ and $\mathrm{CC}$ designed the study and $\mathrm{CC}$ was the principal investigator; $\mathrm{AB}$ was responsible for the data collection supported by MM, YS and ML; AB, MA, $\mathrm{CC}, \mathrm{JL}-\mathrm{F}, \mathrm{MR}, \mathrm{IO}$ and $\mathrm{RB}$ were involved in data analysis and interpretation. The final manuscript was written by $\mathrm{AB}, \mathrm{MA}$ and CC with contributions from the other authors. All the authors read and approved the submitted version.

Funding This study received funding from project PI18/01703, integrated into the Plan Estatal de I+D+I 2013-2016 and was co-financed by the ISCIII-Subdirección General de Evaluación y Fomento de la investigación and the Fondo Europeo de Desarrollo Regional (FEDER).

Competing interests None declared.

Patient consent for publication Not required.

Ethics approval The study was approved by Clinical Research Ethical Committees at each of the participating centres (2018.100).

Provenance and peer review Not commissioned; externally peer reviewed.

Data availability statement Data are not available.

Open access This is an open access article distributed in accordance with the Creative Commons Attribution Non Commercial (CC BY-NC 4.0) license, which permits others to distribute, remix, adapt, build upon this work noncommercially, and license their derivative works on different terms, provided the original work is properly cited, appropriate credit is given, any changes made indicated, and the use is noncommercial. See: http://creativecommons.org/licenses/by-nc/4. $0 /$.

\section{ORCID iDs}

Alazne Belar http://orcid.org/0000-0002-4831-5218

Carlos Centeno http://orcid.org/0000-0003-3395-7039

\section{REFERENCES}

1 Monforte-Royo C, Villavicencio-Chávez C, Tomás-Sábado J, et al. The wish to hasten death: a review of clinical studies. Psychooncology 2011;20:795-804. 
2 Wilson KG, Scott JF, Graham ID, et al. Attitudes of terminally ill patients toward euthanasia and physician-assisted suicide. Arch Intern Med 2000;160:2454-60.

3 Breitbart W, Rosenfeld B, Pessin H, et al. Depression, hopelessness, and desire for hastened death in terminally ill patients with cancer. JAMA 2000;284:2907-11.

4 Monforte-Royo C, Villavicencio-Chávez C, Tomás-Sábado J, et al. What lies behind the wish to hasten death? a systematic review and meta-ethnography from the perspective of patients. PLoS One 2012;7:e37117.

5 Rodríguez-Prat A, Balaguer A, Booth A, et al. Understanding patients' experiences of the wish to hasten death: an updated and expanded systematic review and meta-ethnography. BMJ Open 2017;7:e016659.

6 Galushko M, Strupp J, Walisko-Waniek J, et al. Validation of the German version of the schedule of attitudes toward Hastened death (SAHD-D) with patients in palliative care. Palliat Support Care 2015;13:713-23.

7 Ohnsorge K, Rehmann-Sutter C, Streeck N, et al. Wishes to die at the end of life and subjective experience of four different typical dying trajectories. A qualitative interview study. PLoS One . 2019;14:e210784-26.

8 Chochinov HM, Wilson KG, Enns M, et al. Depression, hopelessness, and suicidal ideation in the terminally ill. Psychosomatics 1998;39:366-70.

9 Ohnsorge K, Gudat H, Rehmann-Sutter C. Intentions in wishes to die: analysis and a typology--a report of 30 qualitative case studies of terminally ill cancer patients in palliative care. Psychooncology 2014;23:1021-6.

10 Rehmann-Sutter C, Gudat H, Ohnsorge K. The patient's wish to die. research, ethics and palliative care. Oxford University Press: Oxford, 2015.

11 Chochinov HM, Wilson KG, Enns M, et al. Desire for death in the terminally ill. Am J Psychiatry 1995;152:1185-91.

12 Kelly B, Burnett P, Pelusi D, et al. Terminally ill cancer patients' wish to hasten death. Palliat Med 2002;16:339-45.

13 Kelly B, Burnett P, Pelusi D, et al. Factors associated with the wish to hasten death: a study of patients with terminal illness. Psychol Med 2003;33:75-81.

14 O'Mahony S, Goulet J, Kornblith A, et al. Desire for hastened death, cancer pain and depression: report of a longitudinal observational study. J Pain Symptom Manage 2005;29:446-57.

15 Price A, Lee W, Goodwin L, et al. Prevalence, course and associations of desire for hastened death in a UK palliative population: a cross-sectional study. BMJ Support Palliat Care 2011;1:140-8.

16 Rosenfeld B, Breitbart W, Galietta M, et al. The schedule of attitudes toward hastened death: measuring desire for death in terminally ill cancer patients. Cancer 2000;88:2868-75.

17 Kelly BJ, Burnett PC, Pelusi D, et al. Association between clinician factors and a patient's wish to hasten death: terminally ill cancer patients and their doctors. Psychosomatics 2004;45:311-8.

18 Kelly BJ, Pelusi D, Burnett PC, et al. The prevalence of psychiatric disorder and the wish to hasten death among terminally ill cancer patients. Palliat Support Care 2004;2:163-9.
19 Wilson KG, Dalgleish TL, Chochinov HM, et al. Mental disorders and the desire for death in patients receiving palliative care for cancer. BMJ Support Palliat Care 2016;6:170-7.

20 Julião M, Barbosa A, Oliveira F, et al. Prevalence and factors associated with desire for death in patients with advanced disease: results from a Portuguese cross-sectional study. Psychosomatics 2013;54:451-7.

21 Villavicencio-Chávez C, Monforte-Royo C, Tomás-Sábado $\mathrm{J}$, et al. Physical and psychological factors and the wish to hasten death in advanced cancer patients. Psychooncology 2014;23:1125-32.

22 Bellido-Pérez M, Crespo I, Wilson KG, et al. Assessment of the wish to hasten death in patients with advanced cancer: a comparison of 2 different approaches. Psychooncology 2018;27:1538-44.

23 Porta-Sales J, Crespo I, Monforte-Royo C, et al. The clinical evaluation of the wish to hasten death is not upsetting for advanced cancer patients: a cross-sectional study. Palliat Med 2019;33:570-7.

24 Monforte-Royo C, Crespo I, Rodríguez-Prat A, et al. The role of perceived dignity and control in the wish to hasten death among advanced cancer patients: a mediation model. Psychooncology 2018;27:2840-6.

25 Bruera E, Kuehn N, Miller MJ, et al. The edmonton symptom assessment system (ESAs): a simple method for the assessment of palliative care patients. J Palliat Care 1991;7:6-9.

26 Carvajal A, Centeno C, Watson R, et al. A comprehensive study of psychometric properties of the Edmonton symptom assessment system (ESAS) in Spanish advanced cancer patients. Eur J Cancer 2011;47:1863-72.

27 Julião M, Nunes B, Barbosa A. Prevalence and factors associated with demoralization syndrome in patients with advanced disease: results from a cross-sectional Portuguese study. Palliat Support Care 2016;14:468-73.

28 Dazzi T, Gribble R, Wessely S, et al. Does asking about suicide and related behaviours induce suicidal ideation? what is the evidence? Psychol Med 2014;44:3361-3.

29 Meerwijk EL, Parekh A, Oquendo MA, et al. Direct versus indirect psychosocial and behavioural interventions to prevent suicide and suicide attempts: a systematic review and metaanalysis. Lancet Psychiatry 2016;3:544-54.

30 Schroepfer TA. Mind frames towards dying and factors motivating their adoption by terminally ill elders. J Gerontol B Psychol Sci Soc Sci 2006;61:S129-39.

31 Balaguer A, Monforte-Royo C, Porta-Sales J, et al. An international consensus definition of the wish to hasten death and its related factors. PLoS One 2016;11:e0146184.

32 Robinson S, Kissane DW, Brooker J, et al. The relationship between poor quality of life and desire to hasten death: a multiple mediation model examining the contributions of depression, demoralization, loss of control, and low Selfworth. J Pain Symptom Manage 2017;53:243-9.

33 Branigan M. Desire for hastened death: exploring the emotions and the ethics. Curr Opin Support Palliat Care 2015;9:64-71. 